\title{
Phase transformation and evolution of dislocation structure in the $\beta$ phase of Ti-17 alloy during hot deformation
}

\author{
K. Yamanaka ${ }^{a,}{ }^{*}$, M. Mori ${ }^{b}$, H. Matsumoto ${ }^{c}$, A. Chiba ${ }^{a}$ \\ ${ }^{a}$ Institute for Materials Research, Tohoku University, Sendai, Japan \\ ${ }^{\mathrm{b}}$ Department of Materials and Environmental Engineering, National Institute of Technology, Sendai College, Natori, Japan \\ ${ }^{\mathrm{c}}$ Department of Advanced Materials Science, Faculty of Engineering, Kagawa University, Takamatsu, Japan \\ *k_yamanaka@imr.tohoku.ac.jp
}

\section{$\underline{\text { Abstract }}$}

The hot deformation behavior and microstructural evolution of Ti-5Al-2Sn-2Zr-4Mo-4Cr (Ti-17) alloy in the $\beta$-phase field were examined. Hot compression tests were conducted at temperatures ranging from 700 and $1100{ }^{\circ} \mathrm{C}$ and strain rates ranging from $10^{-3}$ to $1 \mathrm{~s}^{-1}$. The obtained true stress-true strain curves exhibited steadystate flow behavior at temperatures above the $\beta$-transus temperature $\left(T_{\beta} \sim 890^{\circ} \mathrm{C}\right)$. The microstructural observations suggested that the dynamic recovery process represents a dominant mechanism for the $\beta$-phase of the alloy. In contrast, the flow softening was identified at $700{ }^{\circ} \mathrm{C}$ at a strain rate of $10^{-3} \mathrm{~s}^{-1}$. The formation of fine acicular $\alpha$ microstructures was noticed in such a deformation condition, indicating that dynamic phase transformation can occur in the metastable $\beta$-phase during hot deformation. Such a dynamic phase transformation also occurred preferentially at the initial $\beta$-grain boundaries as well as sub-boundaries that created within the $\beta$ matrix via dynamic recovery. The $\beta$-processing conditions were also examined by constructing processing maps based on the dynamic materials model (DMM).

\section{Introduction}

$\mathrm{Ti}-5 \mathrm{Al}-2 \mathrm{Sn}-2 \mathrm{Zr}-4 \mathrm{Mo}-4 \mathrm{Cr}$ (Ti-17) alloy is a near- $\beta$-type titanium alloy and was first developed by General Electric in the 1970s [1]. The alloy is commonly has been used to manufacture fan blades and compressor disks for aircraft engines, owing to its high strength, superior fracture toughness, and excellent creep properties [2]. In general, turbine disks made of the alloy are manufactured via a series of hot forging process, including breakdown forging, $\alpha+\beta$ forging, and $\beta$ processing. A lot of studies on the hot deformation behavior of Ti-17 alloy have been reported [3-10]. Wang et al. [3] conducted isothermal compression tests on Ti-17 alloy with an initial lamellar microstructure to investigate its dynamic globularization kinetics under deformation conditions. Matsumoto et al. [8] examined the microstructural conversion mechanisms of Ti-17 alloy during hot deformation and developed the constitutive models for microstructural predictions using finite element simulation. However, most of the previous studies have focused on the $\alpha+\beta$ duplex phase region. In contrast, ingot breakdown is performed in the temperature region where the $\beta$ phase is thermodynamically stable [11]. Furthermore, the enhanced creep performance and fracture toughness are realized in the final $\beta$ processing stage where fine acicular $\alpha$ microstructures are produced. This process also starts with a single $\beta$ microstructure and the $\alpha$-phase precipitation occurs during and after hot deformation. Therefore, an in-depth understanding on the hot deformation in the $\beta$-phase field is of critical importance for optimizing the hot-forging process of the alloy and predicting the precipitation behavior of the $\alpha$-phase.

In this study, we examined the hot deformation behavior and microstructural evolution of the $\beta$-phase of a Ti-17 alloy by conducting hot compression tests under varying deformation conditions. The dynamic $\beta \rightarrow \alpha$ phase transformation was observed for the first time. Furthermore, processing maps based on the dynamic materials model (DMM) $[12,13]$ were constructed for optimizing the process parameters for the $\beta$ forging stage.

\section{Material and experiments}

A Ti-17 alloy with the chemical composition of Ti- $4.89 \mathrm{Al}-2.00 \mathrm{Sn}-1.92 \mathrm{Zr}-3.82 \mathrm{Cr}-3.93 \mathrm{Mo}-0.09 \mathrm{Fe}-0.014 \mathrm{Si}-0.102 \mathrm{O}-0.01 \mathrm{C}$ (wt.\%) was utilized in this work. Cylindrical specimens of $8 \mathrm{~mm}$ diameter and $12 \mathrm{~mm}$ height were cut from the as-received material by electrical discharge machining and then annealed at $900{ }^{\circ} \mathrm{C}$ for $3 \mathrm{~h}$ in vacuum, followed by Ar gas cooling.

Uniaxial hot compression tests were performed under vacuum using a thermomechanical processing simulator (Thermecmastor-Z, Fuji Electronic Industrial Co., Ltd., Japan) by varying the deformation temperature $(T)$ between 700 and $1100{ }^{\circ} \mathrm{C}$ and the strain rate $(\dot{\mathcal{\varepsilon}})$ between $10^{-3}$ and $1 \mathrm{~s}^{-1}$. The specimens were heated to the 
deformation temperature at a heating rate of $5 \mathrm{~K} \mathrm{~s}^{-1}$ via high-frequency induction heating, homogenized for $300 \mathrm{~s}$, and then deformed to a reduction in height of $50 \%$, which was approximately equivalent to a true strain $(\varepsilon)$ of 0.7 . After compression, the specimens were quenched to room temperature using a mixture of $\mathrm{N}_{2}$ and $\mathrm{He}_{\mathrm{e}}$ gases.

Microstructural observations were carried out via scanning electron microscopy (SEM), electron backscatter diffraction (EBSD), and X-ray diffraction (XRD). The specimens before and after hot compression tests were sectioned along with the compression axis (C.A.) through the center of the bottom surface, then mechanically ground with emery paper and polished with a $0.3-\mu \mathrm{m}$ alumina suspension. Finally, mirror-like finishing was performed using a $0.04-\mu \mathrm{m}$ colloidal silica solution. SEM observations were conducted at the center of the specimens using JEOL JXA-8430F at an accelerating voltage of $15 \mathrm{kV}$. EBSD scans were performed using field-emission SEM (FEI XL30S-FEG) at an accelerating voltage of $20 \mathrm{kV}$. The processing and analysis of the obtained EBSD data were conducted using TSL OIM. The step sizes were set to 2-10 $\mu \mathrm{m}$, depending on the magnification. XRD measurements were performed using a X-ray diffractometer (PANalytical X'pert PRO MPD) using Cu K $\alpha$ radiation.

\section{$\underline{\text { Results and discussion }}$}

Initial microstructure

Figure 1 shows the backscatter electron (BSE) image and inverse pole figure (IPF) map of the alloy after annealing at $900{ }^{\circ} \mathrm{C}$ for $3 \mathrm{~h}$ in vacuum, followed by Ar gas cooling. The initial microstructure consisted of coarse equiaxed $\beta$-grains with an average grain size of $811 \mu \mathrm{m}$. No precipitation of the $\alpha$-phase was identified either by SEM or EBSD.


Figure 1. (a) BSE image and (b) IPF map of the initial microstructure prior to hot compression testing. In the IPF map, low angle boundaries $\left(2^{\circ} \leq \theta<15^{\circ}\right)$ and high angle boundaries $(\theta \geq$ $15^{\circ}$ ) are denoted by white and black lines, respectively.

Hot deformation behavior

Figure 2 shows the true stress-true strain $(\sigma-\varepsilon)$ curves for the Ti-17 alloy specimens, as obtained by hot compression testing. The obtained $\sigma-\varepsilon$ curves showed a general trend that the flow stress increased with increasing strain rate and decreasing deformation temperature. All the deformation conditions at temperatures above the $\beta$ transus temperature $\left(T_{\beta} \sim 890{ }^{\circ} \mathrm{C}\right)$ resulted in an initial work hardening, followed by steady-state flow at higher strain. In our previous study [14], we developed the constitutive equations for high temperature deformation of Ti-17 alloy in the $\beta$-stable region and revealed that with increasing applied strain, the apparent activation energy for hot deformation monotonously decreased to approximately $190 \mathrm{~kJ} \mathrm{~mol}^{-1}$, which was close to the activation energy of self-diffusion in $\beta$-Ti. Therefore, it can be concluded that dynamic recovery is a dominant mechanism during the hot deformation of the $\beta$-phase in Ti-17.

On the other hand, the hot deformation at temperatures below $T_{\beta}$ showed a different behavior in the obtained $\sigma-\varepsilon$ curves. A significant flow softening was observed at $700{ }^{\circ} \mathrm{C}$ at a strain rate of $10^{-3} \mathrm{~s}^{-1}$. The flow softening became diminished with increasing strain rate, replacing it with monotonous work hardening. It should be noted that the remarkable flow softening observed at $700{ }^{\circ} \mathrm{C}$ at a strain rate of $1 \mathrm{~s}^{-1}$ was associated with adiabatic shear banding. The steady state flow behavior was also identified at $800^{\circ} \mathrm{C}$ in spite that this temperature is also below $T_{\beta}$ of the alloy. 
(a)

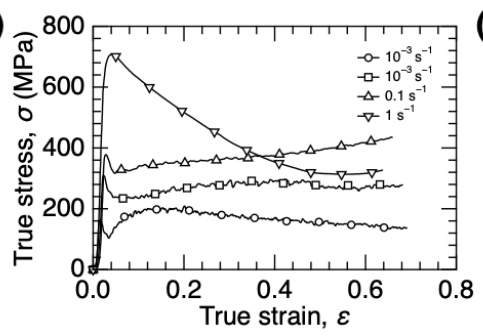

(c)

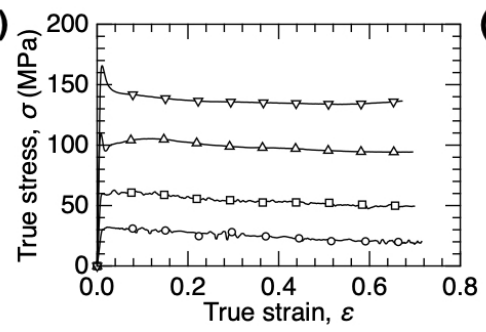

(b)

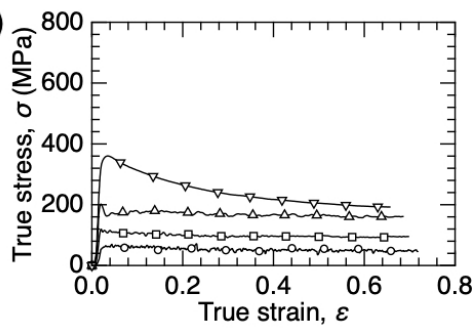

(d)

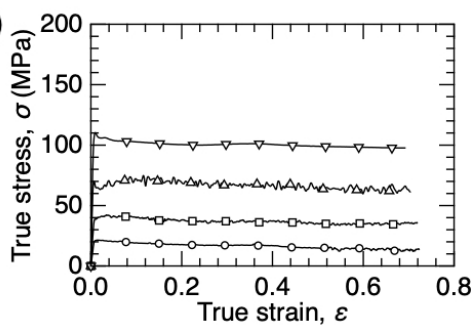

(e)

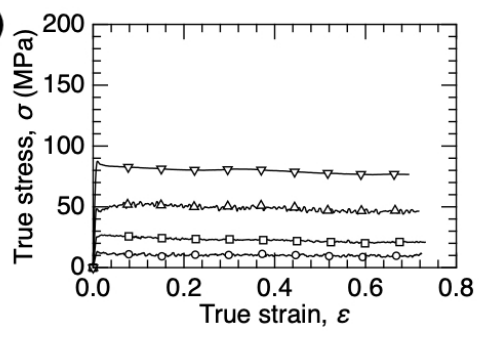

Figure 2. Hot deformation behavior of Ti- 17 alloy with an initial $\beta$-microstructure: (a) $700{ }^{\circ} \mathrm{C}$, (b) $800{ }^{\circ} \mathrm{C}$, (c) $900{ }^{\circ} \mathrm{C}$, (d) $1000^{\circ} \mathrm{C}$, and (e) $1100{ }^{\circ} \mathrm{C}$.

Microstructure evolution

Figures 3 shows the representative microstructural evolution of Ti-17 alloy during hot deformation to $50 \%$. The hot deformation at temperatures below $T_{\beta}$ ( 700 and $800{ }^{\circ} \mathrm{C}$ ) produced acicular microstructures preferentially in the vicinity of the initial $\beta$-grain boundaries as well as sub-boundaries that created within the $\beta$ matrix via dynamic recovery. Such a microstructure evolution was more significant under the lower temperature and/or lower strain rate conditions and after compression to $50 \%$, a fully acicular microstructure was obtained at $700{ }^{\circ} \mathrm{C}$ at a strain rate of $10^{-3} \mathrm{~s}^{-1}$. The formation of acicular precipitation occurred preferentially at the original $\beta$-grain boundaries as well as at subboundaries that created within the $\beta$ matrix via dynamic recovery.

In contrast, such acicular microstructures were not identified in the specimens deformed at the $\beta$-stable temperatures $\left(900-1100{ }^{\circ} \mathrm{C}\right)$. Instead, equiaxed substructures, which were produced via dynamic recovery, were observed within the $\beta$-grains. Increasing the strain rate reduced the average size of these subgrains, although such a microstructural evolution preferably occurred in the vicinity of the initial $\beta$-grain boundaries. 
(a)


(b)

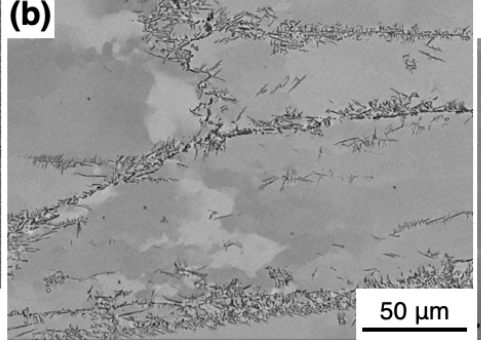

(e)
$50 \mu \mathrm{m}$

(c)

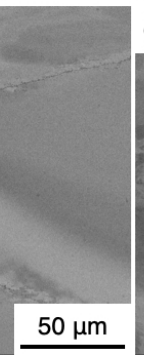

(f)
$50 \mu \mathrm{m}$

$50 \mu \mathrm{m}$

Figure 3. BSE images of Ti-17 alloy deformed to $50 \%$ at strain rates of $(\mathrm{a}-\mathrm{c}) 10^{-3}$ and $(\mathrm{d}-\mathrm{f}) 0.1 \mathrm{~s}^{-1}$ : (a, d) $700{ }^{\circ} \mathrm{C}$, (b, e) $800{ }^{\circ} \mathrm{C}$, and (c, f) $900{ }^{\circ} \mathrm{C}$.

Figure 4 represents the XRD patterns of Ti-17 alloy deformed to $50 \%$ at (a) 700 and (b) $800{ }^{\circ} \mathrm{C}$. Although the initial microstructure was composed of single $\beta$ grains, the diffraction peaks of the $\alpha$-phase were clearly identified after hot compression. It can be thus concluded that dynamic phase transformation occurred in the metastable $\beta$-matrix during hot deformation at temperatures below $T_{\beta}$ and this could be a reason for the significant flow softening in the corresponding $\sigma-\varepsilon$ curve.


Figure 4. XRD patterns of Ti- 17 alloy deformed to $50 \%$ at (a) $700{ }^{\circ} \mathrm{C}$ and (b) $800{ }^{\circ} \mathrm{C}$.

Processing maps

Processing map is a concept to optimize the process parameters for hot forging and has been applied for various metals and alloys. The relationship between the heat generated due to plastic deformation and the rate of energy dissipation during microstructural evolution can be obtained using the DMM approach [12,13], which 
assumes that the total energy introduced during plastic deformation is composed of the dissipation energy $G$ and the energy $J$ related to microstructural evolutions such as dynamic recovery and dynamic recrystallization. The power dissipation efficiency $\eta$ is a function of the strain rate sensitivity $(m)$ and can be described as follows:

$$
\eta=\frac{2 m}{m+1}
$$

On the other hand, the instability criterion defined by Ziegler [15] is based on the extreme principles of irreversible thermodynamics applied to a large plastic flow:

$$
\xi(\dot{\varepsilon})=\frac{\partial \ln [m /(1+m)]}{\partial \ln \dot{\varepsilon}}+m<0
$$

This equation considers the principle of the maximum rate of entropy production and flow instability related to various phenomena such as flow localization, cracking, and shear banding, which occur when $\xi(\dot{\varepsilon})$ is negative. Processing maps are typically characterized by the variations in $\eta$ and $\xi(\dot{\varepsilon})$ and can be represented as functions of temperature and strain rate.

Figure 5 shows the processing maps at $\varepsilon=0.6$ for the hot deformation of Ti-17 alloy that initially had a single $\beta$-phase microstructure. The temperature increase due to adiabatic heating during hot deformation was calculated via the following equation [16]:

$$
\Delta T=\frac{\eta_{e}}{\rho c} \int_{0}^{\varepsilon} \sigma d \varepsilon=\frac{\eta_{e}}{\rho c} W
$$

where $\Delta T$ is the temperature increase due to the work imposed on the sample, $\eta_{e}(=0.95)$ is the fraction of mechanical work transformed to heat, $\rho$ is the density of the sample, $c$ is the heat capacity of the material, and $W$ is the sample power input. The power dissipation efficiency map (Fig. 5(a)) shows that increasing $\dot{\vec{\varepsilon}}$ decreases the $\eta$ value at a given temperature and a high $\eta$ domain is observed at lower strain rates. Furthermore, the maximum value of $\eta$ increases with increasing $\varepsilon$ [14] and ultimately reaches a magnitude of approximately $60 \%$ at $\varepsilon=0.6$. In general, the higher value of $\eta$ indicates that significant microstructural evolution occurs during hot deformation. Therefore, the higher $\eta$ values at lower $\dot{\varepsilon}$ agree well with the actual microstructural evolution and can be interpreted in terms of the occurrence of dynamic phase transformation and dynamic recovery at temperatures below and above $T_{\beta}$, respectively. On the other hand, the flow instability map in Fig. 5(b) shows that unstable deformation conditions exist only at high strain rates $\left(\dot{\varepsilon}>0.1 \mathrm{~s}^{-1}\right)$ regardless of the deformation temperature. This indicates that flow instability exists at the high strain rate conditions and is reasonable because shear banding was identified at $1 \mathrm{~s}^{-1}$, in particular at $700{ }^{\circ} \mathrm{C}$.
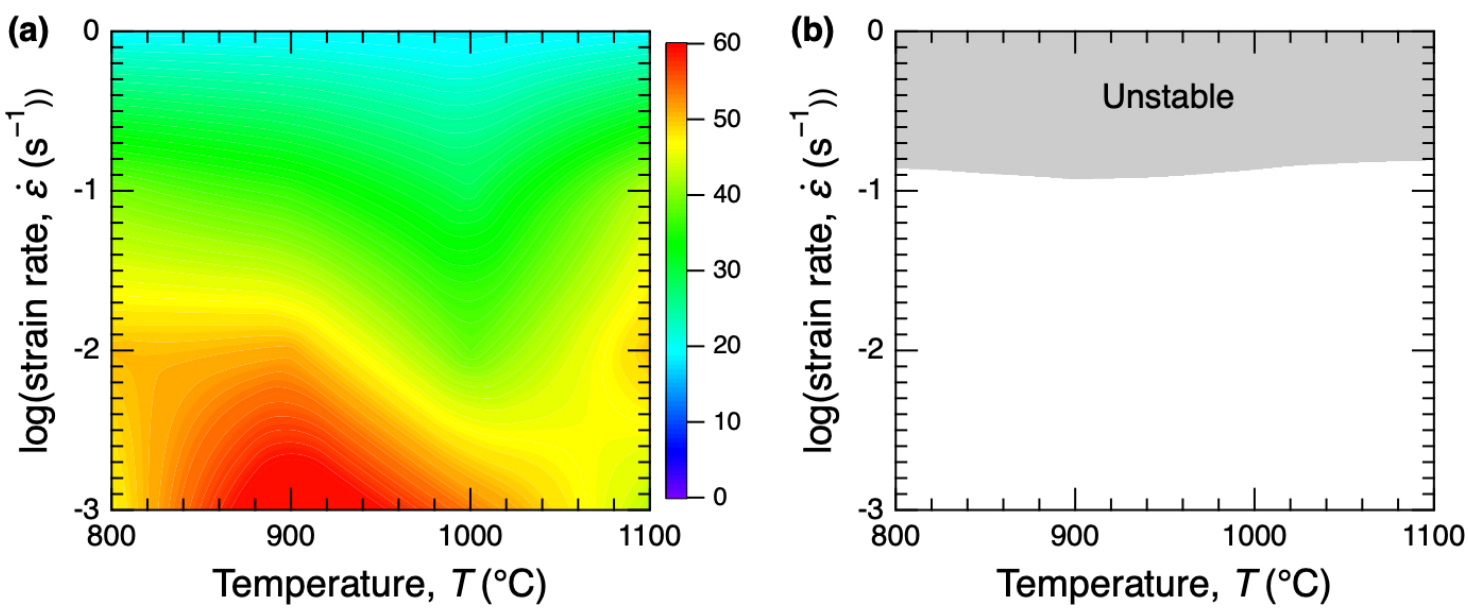

Figure 5. Processing maps for Ti-17 alloy deformed in the $\beta$-phase field: (a) power dissipation efficiency map and (b) flow instability map obtained at $\varepsilon=0.6$.

\section{Conclusion}


In this study, we conducted the hot compression tests of Ti-17 alloy with a single $\beta$-phase as an initial microstructure and examined the hot deformation behavior and microstructural evolution. The obtained true stress-true strain curves exhibited steady-state flow behavior at temperatures above $T_{\beta}$. Dynamic recovery played a dominant role in such deformation conditions, resulting in significant substructure development within the $\beta$-grains in particular at lower strain rates. In contrast, the dynamic phase transformation to produce acicular $\alpha$ microstructures in the metastable $\beta$-phase matrix during hot deformation was identified at temperatures below $T_{\beta}$. The nucleation of the $\alpha$-phase was observed at the prior $\beta$-grain boundaries as well as subboundaries introduced via dynamic recovery that occurred at the earlier stage of the deformation.The processing maps developed using the data agreed well with the actual microstructural evolution observed. The obtained knowledge could be useful in optimizing the $\beta$-forging stage of the alloy.

\section{Acknowledgement}

This study was funded by the Council for Science, Technology, and Innovation (CSTI), the Cross-ministerial Strategic Innovation Promotion Program (SIP), and the "Process Innovation for Super Heat-Resistant Metals (PRISM)" (Funding agency: JST). It was also supported by the cooperative program of the Cooperative Research and Development Center for Advanced Materials, Institute for Materials Research, Tohoku University. K. Yamanaka acknowledges the financial support fromthe Light Metal Educational Foundation, Inc., Japan.

\section{$\underline{\text { References }}$}

[1] R. Boyer, H. Rosenberg, Beta Titanium Alloys in the 1980's, TMS-AIME Publications, Warrendale, PA, 1984.

[2] K. Firm, R. Boyer, G. Welsch, ASM Int. Mater. Park. OH (1994) xxii 1176.

[3] K. Wang, W. Zeng, Y. Zhao, Y. Lai, Y. Zhou, Mater. Sci. Eng. A 527 (2010) 2559.

[4] K.X. Wang, W.D. Zeng, Y.Q. Zhao, Y.T. Shao, Y.G. Zhou, Mater. Sci. Eng. A 527 (2010) 6193.

[5] K. Wang, W. Zeng, Y. Zhao, Y. Lai, Y. Zhou, J. Mater. Sci. 45 (2010) 5883.

[6] K.X. Wang, W.D. Zeng, Y.Q. Zhao, Y.J. Lai, X.M. Zhang, Y.G. Zhou, Mater. Sci. Technol. 27 (2011) 21

[7] S.H. Chen, M.C. Zhang, M.L. Jia, W. Li, J. Mater. Process. Technol. 252 (2018) 148.

[8] H. Matsumoto, D. Naito, K. Miyoshi, K. Yamanaka, A. Chiba, Y. Yamabe-Mitarai, Sci. Technol. Adv. Mater. 18 (2017) 893.

[9] Z. Zhao, H. Guo, X. Wang, Z. Yao, J. Mater. Process. Technol. 209 (2009) 5509.

[10] Z. Zhao, H. Guo, Z. Yao, Mater. Sci. Eng. A 549 (2012) 193.

[11] I. Weiss, S.L. Semiatin, Mater. Sci. Eng. A 243 (1998) 46.

[12] Y.V.R.K. Prasad, T. Seshacharyulu, Int. Mater. Rev. 43 (1998) 243.

[13] Y.V.R.K. Prasad, H.L. Gegel, S.M. Doraivelu, J.C. Malas, J.T. Morgan, K.A. Lark, D.R. Barker, Metall. Trans. A 15 (1984) 1883.

[14] K. Yamanaka, H. Matsumoto, A. Chiba, Adv. Eng. Mater. 21 (2019) 1800775.

[15] H. Ziegler, in:, I. Sneddon, R. Hill (Eds.), Prog. Solid Mech., John Wiley, New York, NY, 1965, pp. 91-193.

[16] R.L. Goetz, S.L. Semiatin, J. Mater. Eng. Perform. 10 (2001) 710. 